\title{
Assisting Voters, Language Access, and the Role of Election Administrators
}

\author{
Jill LaVine and Alice Jarboe
}

Abstract While the federal government under the 1965 Voting Rights Act (VRA) Section 203 requires election jurisdictions to provide language assistance to voters, there is no financial support and not enough detailed information from the government to make this a success. Election jurisdictions must find the location of the voters through extensive outreach programs, mailings, and media efforts. This is a very costly undertaking and often still does not reach the voters who really need the assistance. If a jurisdiction does not meet the needs of their voters needing language assistance, they can be sued by the Department of Justice (DOJ). Community organizations and advocacy groups can be helpful in identifying voters who need assistance, but often they have their own agenda. Election officials want to assist voters for the right reason-so the voter can be an informed voter. But this can be difficult unless we have the information we need, the financial support, and without the constant fear of being sued.

Keywords Language access $\bullet$ Sacramento County $\bullet$ Language support

- Language advocacy organizations • Federal language requirements

J. LaVine $(\bowtie) \bullet$ A. Jarboe

Voters for Sacramento County, Sacramento, CA, USA

(C) The Author(s) 2019

M. Brown et al. (eds.), The Future of Election Administration, Elections, Voting, Technology, https://doi.org/10.1007/978-3-030-18541-1_5 
Voters who are non-English speakers and whose native language is one that has historically been associated with discrimination at the polls (Asian, Alaskan Native, Native American, and Spanish) are entitled to language assistance under the Voting Rights Act (VRA). Sacramento County has been covered under VRA Section 203 for Spanish language for almost 20 years and for Chinese language starting in 2011. In addition, any California jurisdiction that has a non-English speaking population of any language that meets a $3 \%$ threshold is also covered under state law. For Sacramento, this means that there are five languages in addition to Spanish and Chinese that have language coverage, including Hmong, Korean, Punjabi, Tagalog, and Vietnamese. For our county's 500 polling places, about 200 of them are staffed with a Spanish speaker. We have about 20,000 registered voters who want materials in Spanish.

The concept of providing language assistance seems relatively simpleprovide voting materials to voters in English and another language-but it is a complex undertaking. On a primary ballot, for example, the possibility of 7 languages times 9 parties at each polling place means there could be 63 different versions of every ballot. The cost is high both in potential for precinct worker confusion and in budget requirements.

\section{Who And How This Work Is Done}

The work of providing language assistance is part of everyone's job inside an election office. Outreach takes the lead on this, but registration staff has to correctly enter the information, another unit needs to prepare the ballot design, and another unit develops the precinct worker training. Still other units are responsible for adjudicating cast ballots, budgeting for the additional language support, and overall management of the language access program. There are also community groups that assist with registration and identifying needs. For example, the CAPITAL (Council of Asian Pacific Islanders Together for Advocacy and Leadership) group has meetings and election office outreach staff attend to encourage registrations. Much of this work is done by outreach staff after normal work hours.

One of the hardest parts of offering language assistance is planning the staffing needs for language speakers at the polls on Election Day. California law requires that a precinct worker is there the entire time, from opening to closing. In addition, we have an internal assessment to test workers on languages, and our outreach staff also tests the potential workers. Members of the Chinese community in particular will volunteer to come for a few hours 
to work on Election Day but not for the entire day. County and state employees like social workers are more helpful as they will work through Election Day and they are already certified in the language. If a potential voter comes to a polling place that does not have a language speaker to help them, we have a phone service, LanguageLink, a live language translation service that serves a voter in most languages, in a three-way conversation. The election office pays for this phone-based service out of the election budget.

\section{ISSUES WITH OUTREACH}

One of the most challenging issues that election officials face in language coverage is identifying the voters who need language assistance and understanding their cultural needs. In some cases, people will read the same language but speak it differently (e.g., Mandarin Chinese and Cantonese Chinese), so, although these voters use the same printed ballot style, they need different audio versions. There are also differences in demand by age of voters. The older generation wants their ballots in Chinese; the younger generation wants their ballots in English.

The Department of Justice (DOJ) has suggested that the election office search its voter registration rolls for voters with particular surnames in order to identify group members and their locations. It doesn't workpeople intermarry, and change names, and surnames are dispersed across the county. We can use birthplaces because we get that information on the California voter registration form, but if they come to the US at an early age, they speak English. Birthplace information is not on the federal voter registration form, so if voters register through the federal form the information is not available. The Geographic Information System (GIS) staff take the birthplace information from the Census and mail information to voters asking about language preference. When that information comes back, registration staff marks the voter's file with their preferred language, and then input this into a GIS map so we can also identify which polling places will need that language support.

In the case of identifying those who may need Spanish assistance, we mailed out response cards to all voters-and have identified 500 from the cards. In addition, we had outreach staff at their community activities and groups. The resources we've invested in trying to find out who needs this assistance is tremendous.

We also had to quickly learn Chinese cultural norms before we could go to their outreach events. Colors, clothes, particular greetings matter at 
certain meetings - for example, we avoid wearing white because it is tied to death. We also learned there was a Chinese group that supported one political cause in China and they wanted us to advertise in their newspaper, while another group said, "Don't you dare or we'll not participate with you anymore." So we had to choose which newspaper would reach the largest number of voters in the most positive way with a limited budget.

Another issue occurs when we place the Chinese translation portions on our ballots. We put all three languages (English, Spanish, and Chinese) on one ballot and on all of our materials. If we place the Chinese version first, people get angry and contact us about the wasted cost. If we don't put all the languages on one card then we may not reach that one voter and the DOJ comes after us.

\section{Outreach}

Outreach staff have a tough job. There is a mismatch between the population the Census captures and the actual market for language assistance within the community. The Census data doesn't provide enough specific information about the particular people who need language assistance. This makes our job harder, and if we are noncompliant, we can be sued. The data from the American Community Survey (ACS) is organized by Census tract, however, California doesn't use Census tracts for voting precincts, they don't match up with district lines. ACS now reports population estimates from Census data every five years instead of ten, which will likely increase demands for language assistance and also give us more information.

Marketing to those who may need language assistance is also very challenging. We don't have a local Chinese paper or radio or TV station; these media outlets come out of San Francisco. As a result, anything we advertise or promote has to be generic; outlets won't pick it up if the information is specific to Sacramento only. There are no outlets for Tagalog, Vietnamese, Hmong, Korean, or Punjabi.

\section{The Role of Advocacy Organizations}

In the beginning, we didn't have information on where the people who needed assistance were concentrated, and advocacy groups pushed us to do this work. In response, we mailed everything in two languages. The expense related to this practice was significant, as anything election related 
has to have a court certified translation in compliance with California Election Code.

Other advocacy groups regularly monitor our polling places to make sure we are doing what we are supposed to as well as what they want us to do. They provide us feedback after elections noting what needs to be improved, and sometimes this is helpful, though at other times the advocates are not correct and have their own agenda. We work with these groups to improve their feedback by attending meetings in which they train their observers. California Election Code is complex and the observers often do not know what to look for.

\section{Costs}

We do not have enough support to do this. We are pulled very thin. A Chinese speaking staff member has to work at the front counter, do outreach in the community, work at precincts, check voter registration cards, figure out how to enter that into our system, speak to the press, and go to citizenship classes to teach about voting. This is also true for our staff Spanish speaker. But we do not have the resources to pay them for all of these levels and types of work-all we can do is give them a language differential.

While language assistance is a federal requirement, there is no federal financial support. Support for language assistance administration comes through a statewide association of counties, the California Association of Clerks and Election Officials (CACEO). For uniformity in the state to comply with the language requirements, we have CACEO as a sounding board. We also run our procedures by our Secretary of State (SOS) for blessing on implementation, but they can't provide their official stamp of approval for legal reasons. While we are not required to provide all election materials in the languages that meet the $3 \%$ state threshold, we are to provide a translated ballot and attempt to find a poll worker to help. We are required by the SOS to report our efforts. The state is supposed to tell us which precincts voters who need language assistance are in based on the ACS data, but they don't.

We are providing language assistance to too many people - or at least it seems that we are providing language assistance to many more than need it or will use it. The Census determinations force us to provide Chinese language assistance but we have had only 500 voters request assistance. Without considering individuals, we are spending $80 \%$ of our money trying to reach the $20 \%$ of the voters who may need assistance. In 2013 , 
implementing outreach and assistance for Spanish language speakers cost the county $\$ 200,000$. Our expense in that year for Chinese language outreach and coverage was equivalent. The expense for other languages is even greater.

\section{How Should We Fix This System?}

It is most important to have language assistance on Election Day. During registration, staff have more time, but on Election Day, there is immediacy. It is a given that the election official will provide the opportunities. It makes sense to make the voter responsible for requesting language help, rather than making elections officials responsible for finding the voter.

There are also multiple voting system issues that come up when adding another language. The voting equipment that we use hasn't caught up to our needs because until just recently we only had one or two languages. Even though our voting system allows us to use different languages, font to support all the languages needed wasn't available or certified by California for use on the system. The vendors were not prepared for the multiple numbers of character-based languages on the same piece of equipment.

In thinking about the issues related to adding Chinese, for example, our voting system was not state-certified for Chinese. This means that our office in conjunction with the voting system vendor had to have the system retested and go back to make corrections. We were under a deadline to get this done but we couldn't get the Chinese piece to work. We really need some type of DRE (direct-recording electronic, or touch screen) machine for something like that-optical scan is simply too limited for the volume and types of languages we have now. But DREs have largely been banned in the state-we are only allowed one per polling place. In our county, we do have Ballot Marking Device (BMD) machines that anyone can vote on, which helps. We have a classification of "voters with specific needs" that covers language and disabilities and we have monthly statewide meetings to work on polling place surveys, accessibility issues, and language requirements, and so on.

A BMD has limitations with the different languages and the required audio files. To address this, we have to increase our BMD machines at each polling place, which increases the cost significantly, and we have to identify where to send the BMDs or send every type of equipment to every polling location. When we add the fourth language, we won't be able to do this, and we will have to target where to send equipment; this is where we get sued. 
There is also a fear of the Department of Justice and the language advocates. When we get sued, it is the county that covers the cost of the lawsuit. It is easier to enter into a consent decree, but then we are bound by the terms of the decree for a specific term even if the issues are resolved or become nonissues in the following years. We never know where the advocates are coming from, and no matter how closely we work with themeven above and beyond what is required in code-it is never enough.

We would like to get rid of the fear and actually just provide the service to those who need it. This is the right thing to do and We would like to do it for that reason.

Open Access This chapter is licensed under the terms of the Creative Commons Attribution 4.0 International License (http://creativecommons.org/licenses/ by $/ 4.0 /)$, which permits use, sharing, adaptation, distribution and reproduction in any medium or format, as long as you give appropriate credit to the original author(s) and the source, provide a link to the Creative Commons licence and indicate if changes were made.

The images or other third party material in this chapter are included in the chapter's Creative Commons licence, unless indicated otherwise in a credit line to the material. If material is not included in the chapter's Creative Commons licence and your intended use is not permitted by statutory regulation or exceeds the permitted use, you will need to obtain permission directly from the copyright holder.

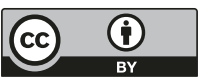

